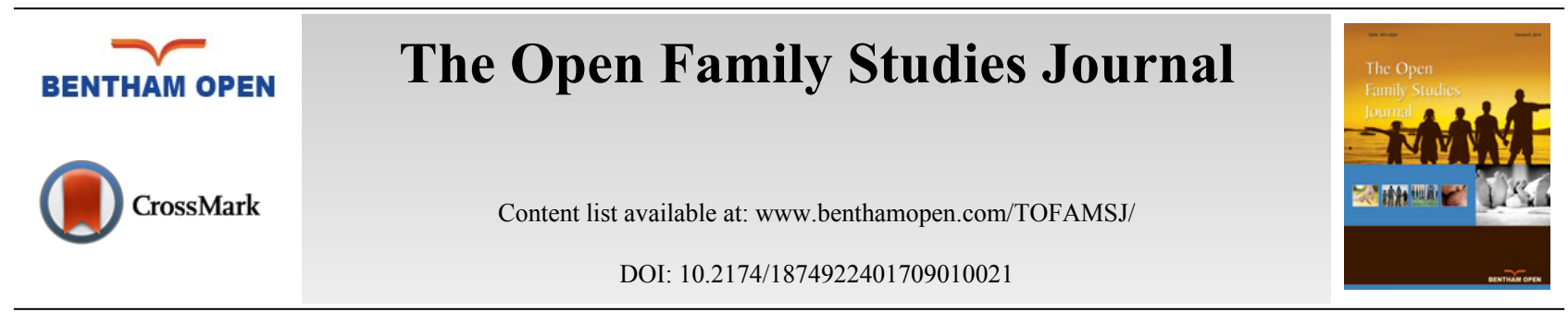

RESEARCH ARTICLE

\title{
Virtual Reality Smoking Cessation-Designed for Teens, by Teens
}

\author{
Brenda K. Wiederhold ${ }^{1,2, *}$, Ian Miller ${ }^{3}$ and Mark D. Wiederhold ${ }^{1}$ \\ ${ }^{I}$ Virtual Reality Medical Center, San Diego, California, USA \\ ${ }^{2}$ Virtual Reality Medical Institute, Brussels, Belgium, Europe \\ ${ }^{3}$ Interactive Media Institute, San Diego, California, USA
}

Received: December 28, 2016

Revised: March 30, 2017

Accepted: May 04, 2017

\begin{abstract}
:
Introduction:

Today, about $90 \%$ of adult smokers started smoking before the age of 18 . As the largest preventable cause of disease and death in the United States, tobacco use accounts for nearly 500,000 deaths and hundreds of billions of dollars to care for smoking-related illnesses every year. While most smoking cessation programs are geared toward adults, there is a void in attempts to curb teen smoking.

\section{Objective:}

With funding from the National Institute on Drug Abuse, the Virtual Reality Medical Center (VRMC) sought to create a more effective way to help teens quit smoking. Utilizing cue exposure therapy to eliminate the association of smoking with objects and activities, the program uses virtual environments containing smoking cues to elicit the addictive behaviors and teach the users how to recognize and resist these triggers.
\end{abstract}

\section{Method:}

In a novel approach, VRMC recruited students from a local high school to aid in the design and development of virtual worlds in order to create an entertaining and effective program for teens. Researchers and the participants of this TeenSmoking program created a variety of anti-smoking environments ranging from scenarios at home, to peer pressure situations at school, all intended to elicit and educate users on addictive smoking behaviors.

\section{Conclusion:}

With past clinical success, researchers at VRMC hope to continue to implement widely available teen smoking cessation programs with enhanced usability, graphics, and multiplayer functionality. Overall, researchers hope to advance more comprehensive use of virtual reality to curb teen smoking addictions.

Keywords: Virtual Reality, Teens, Smoking Cessation, Cue Exposure Therapy, Addictive Smoking Behaviors, Anti-smoking Environments.

\section{INTRODUCTION AND BACKGROUND}

Tobacco use is the single largest preventable cause of disease and death in the United States and has increasingly become a burden on America's health and economic status. Accounting for over 480,000 deaths every year, cigarette smoking-related illnesses in the U.S. cost over $\$ 300$ billion annually [1]. Today, $90 \%$ of adult smokers started smoking before the age of 18. Although these youths have not become regular smokers, they are already addicted [2]. Some teens don't even realize they are addicted, while others are in denial; it has become something their body needs and craves. Whether because of naiveté or defiance, many adolescents do not believe they are at risk of developing smoking

* Address correspondence to this author at the Virtual Reality Medical Center, San Diego, California, USA; Tel: 8586420267; E-mail: b@vrphobia.eu 
related health issues. Many believe they can quit at any time and therefore do not seek cessation assistance. Those who would like help quitting, however, may be unfamiliar with smoking-cessation programs or concerned over temporary challenges such as withdrawal, stress, and mood changes [3].

Probable health risks for adolescent smokers are well established. Aside from the scent smoking a cigarette leaves on their clothes, hair, and breath, teens may not be aware of these adverse effects of smoking. First, smoking can lead to cough and phlegm production, an increase of respiratory illnesses, a decrease of physical performance, changes in blood cholesterol levels, and a reduced rate of lung growth and function. Subsequent long-term effects include heart disease, stroke, lung disease, and cancers of the lung, mouth, pharynx, esophagus and bladder [4].

Some of the reasons adolescents smoke is because it gives them a "buzz;" it gives them something to do when they are bored; it makes them feel more relaxed, they think they look "cool" and more mature; it decreases their appetite to help them to lose weight and it helps them fit in with their friends. They are concerned that quitting smoking will make them irritable and unable to relax [3]. Importantly, they will lose an activity that helps them pass time. They will also have to change their habits and way of life if they discontinue smoking, often a daunting and difficult task [5].

Most smoking cessation programs are geared towards adults, leaving insufficient resources for teen smoking cessation programs [6]. As a result, the Virtual Reality Medical Center (VRMC) launched an online smoking program to help adolescents to kick the habit. With funding from the National Institute on Drug Abuse (NIDA), VRMC sought an effective way to curb teen smoking and encourage teenagers to draw their own conclusions about tobacco. In doing so, VRMC solicited teens to participate in the development and testing of a virtual reality environment to curb teen smoking [7]. Teens favor informal and convenient tobacco cessation support modules as opposed to face-to-face interaction because they feel more comfortable and less inhibited by the anonymity computers offer. As a result, VRMC and its team of teen participants developed the internet site to reach out to teens on familiar and desirable platforms, such as personal computers and smart phones [7]. Not only are these platforms familiar and easy to explore for teens, but the online capability makes them easily accessible across the globe.

\section{TREATMENT}

Cue exposure therapy (CET) uses repeated exposure to eliminate the association of smoking with objects and situations [8]. A more recent iteration of CET utilizes virtual reality as a means of systematic exposure to treat a variety of addictive behaviors [9 - 13]. VRMC's program utilizes virtual environments containing smoking cues such as packs of cigarettes, ashtrays, and peer pressure to elicit the addictive behaviors. This is done so users can see what triggers their cravings. Once they recognize what causes them to want to smoke, they can understand why they crave a cigarette and learn to distract themselves from those desires. In the first virtual environment, smoking cues are placed around the teenager's home. In some cases, users can look at the objects that increase their craving. In other cases, users have the option to throw away the objects. In the second environment, users are at school where they encounter peer pressure to smoke. For example, when offered a cigarette, they can choose to either accept the offer, or to fight their craving by declining it.

Previous research on virtual reality and smoking cessation reveal a wide range of pre-existing applications [14, 15]. In particular, researchers created virtual environments to evoke a desire for nicotine and utilized virtual realityenhanced CET, ultimately finding the advanced technology to be more effective in eliciting craving symptoms than traditional approaches [16].

According to The Smoking Zine [5], some ways to distract teenagers from their cravings include: exercising, listening to or playing music, doodling, cooking, taking naps, stretching, chewing bubble gum, calling a friend, drinking a glass of water, etc. VRMC's TeenSmoking online program incorporated some of these distraction techniques into the game to help instill behaviors in the users that fight their cravings. It also taught them how to avoid potential situations that elicit their cravings. Ultimately, by exposing themselves to the items that trigger their cravings, the users eventually become desensitized to these cues, thus, allowing them to eradicate unconscious cravings and smoking behaviors [8].

\section{VIRTUAL ENVIRONMENT OVERVIEW}

VRMC's TeenSmoking virtual environment consists of two major areas: Home and School.

Home has two floors. The bottom consists of the front door and garage, while the second floor contains a bedroom, kitchen, living room, and a bathroom. In addition to having the choice to take a nap or sleep if they are tired, the user can play several games and partake in activities designed to distract from the desire to smoke. Smoking cues, such as 
cigarettes and ash trays, are placed around the house to increase a user's craving. Faced with choices to leave the stimuli alone, clean it up, or smoke a cigarette, the user is in control of their own behaviors, but must also face the consequences of their decision. For example, smoking a cigarette causes the illustration of the user's lungs to darken and their stamina level to decrease faster. Eventually, if the stamina level decreases too much, the user is prompted to go to bed to recover. Mini games, on the other hand, help reduce cravings but simultaneously decrease the stamina, which can be refilled through napping.

Each user begins the trial in their bedroom presented with a large calendar hanging on the wall. The first task the user must complete is picking a quit date. The user is then able to navigate to different parts of the house. During the navigation, user's stamina slowly decreases while his or her craving to smoke increases. The following Fig. (1) are the snapshots of the home virtual environment designed by teens:

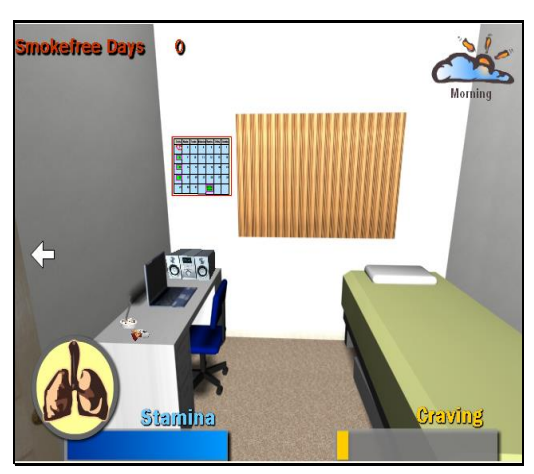

$\underline{\text { Bedroom }}$

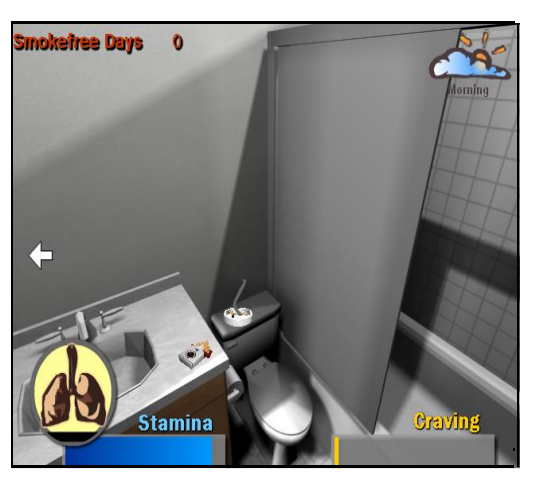

Bathroom

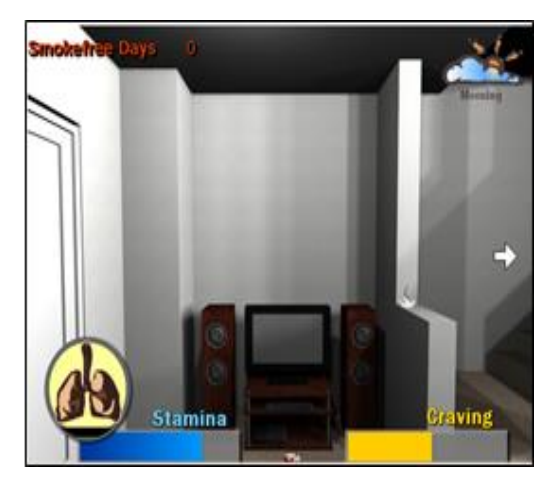

Living Room

Fig. (1). The home environment allows users to navigate throughout different rooms in the house and be exposed to potential smoking cues.

School consists of a classroom (Fig. 2), restroom, and a cafeteria area. Each user can sit in the classroom or interact with classmates during breaks or lunch hours. When the user is on school grounds, peers offer cigarettes to the user and he or she is faced with the challenge of rejecting the craving by playing a mini game or participating in an activity.

\section{Classroom}

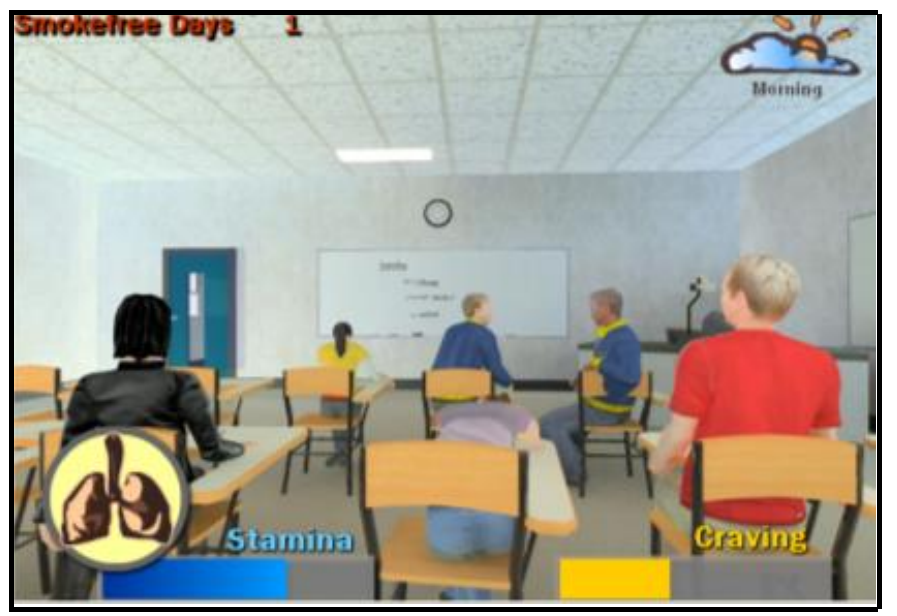

Fig. (2). Students are able to navigate school environments and face situations that they typically associate with a craving. Participants learn successful and effective mechanisms to decrease their craving.

When in the school environment, the user is faced with the challenge of rejecting cigarettes offered by peers. One way to stymie this craving is to play a mini-game. If the user wins the game, he or she has successfully denied the 
craving. However, if the user loses, this signifies giving in to the craving and smoking, consequently resetting the smoke-free day counter. These challenges help the users understand the difficulty of quitting smoking, but emphasize that with determination and the right attitude, one can eventually succeed, an important paradigm for real-life. These games are randomly selected to make the program more appealing to the user and are also more challenging than the games in the home environment because they include smoking cues that tempt the user.

User's stamina has gone down after doing several activities during the day. The lung is darkened indicating the user has been smoking, and hence the low craving level, which is shown on the lower right hand corner of the screen.

The real-time report that is shown on the right-hand side of the web browser illustrates the actions taken by the user, and the current health status.

On school days, user goes to school by driving his/her car that is parked in the garage.

Detailed 3D scene gives user a higher sense of immersion. Here, the user can choose to drive to school or go back to the house.

\section{PROGRAM FUNCTIONALITIES}

The following (Table 1 and Fig. 3) outlines the functionalities available to each user.

Table 1. Participants can navigate between the home and school environments and play a multitude of mini games designed to decrease students' smoking cravings.

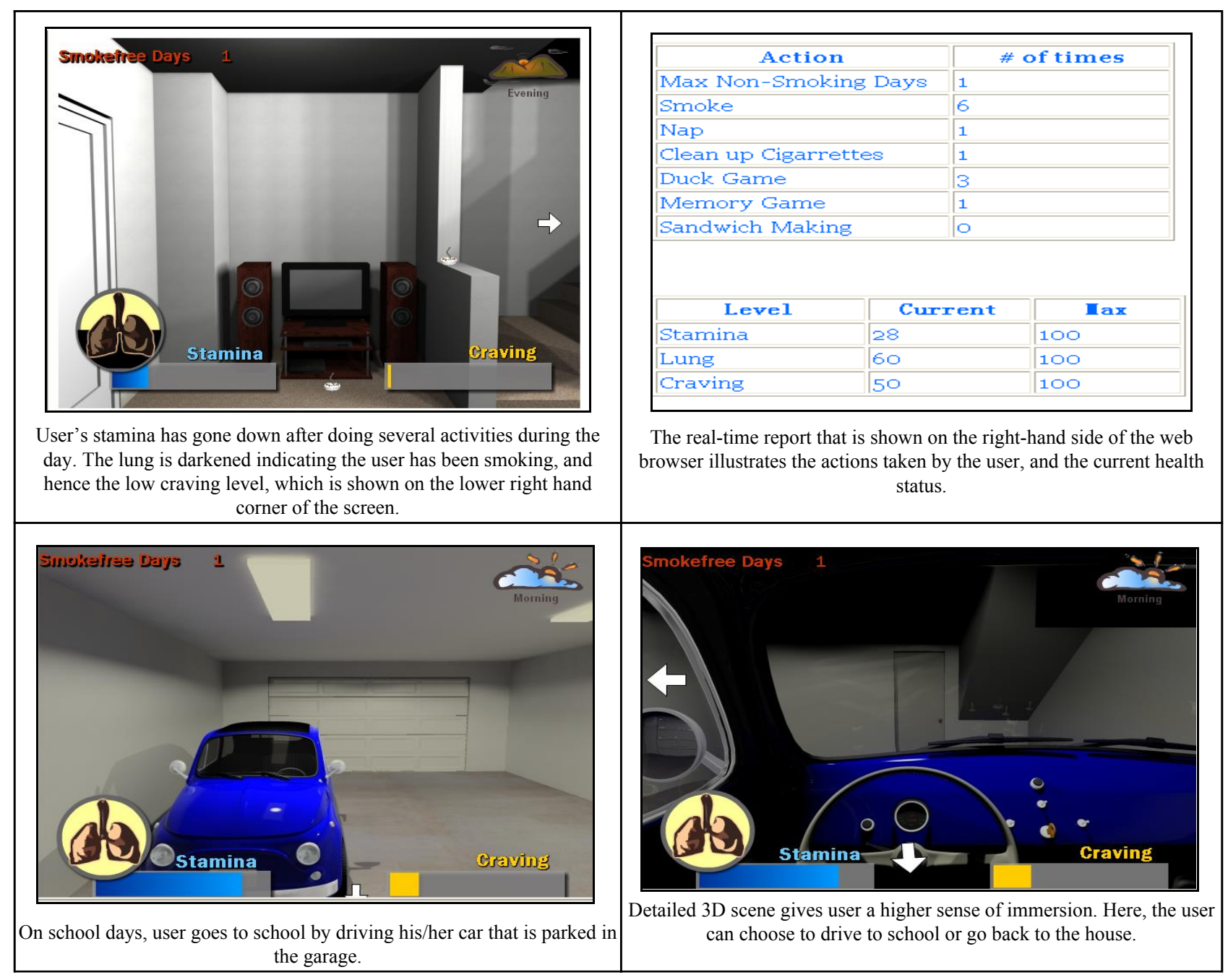


(Table 1) contd.....

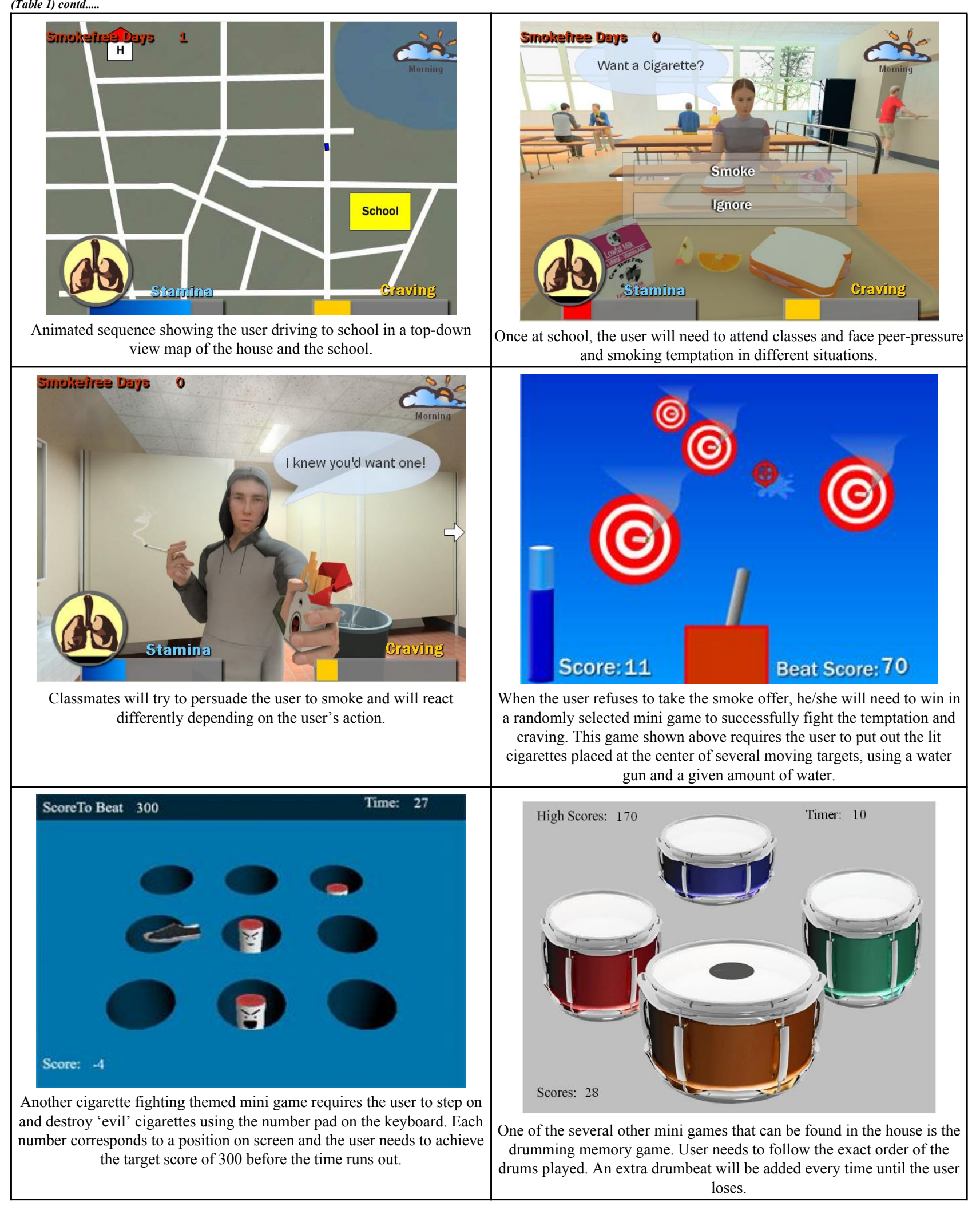


(Table 1) contd.....

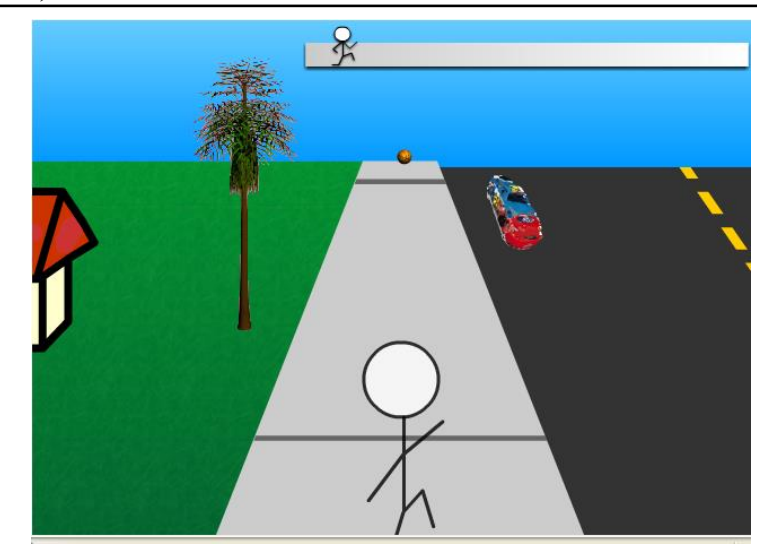

User's lung gets darker every time he/she takes a smoke. To restore the lung back to a healthy condition, he/she will need to do exercise, just like in real-life. This game can be played at the user's room by selecting the treadmill under the bed.

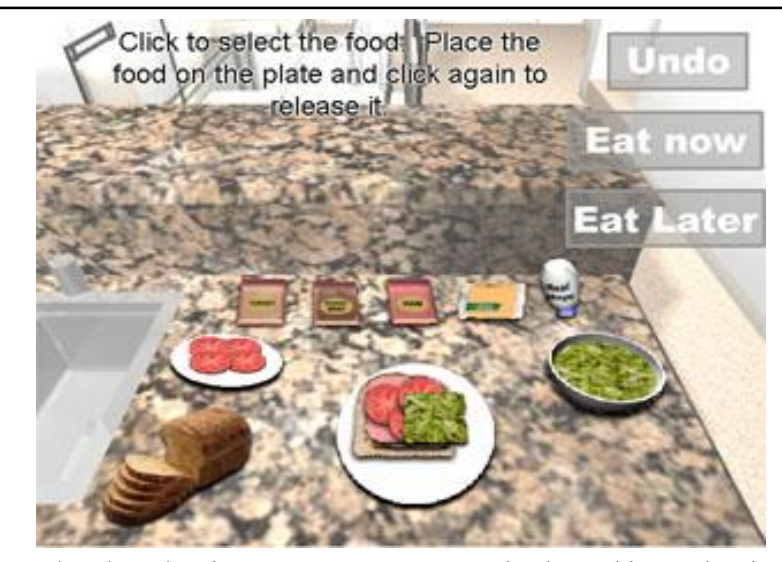

Rather than sleeping, users can restore stamina by making and eating food. He/she can make his/her own sandwich in the kitchen.

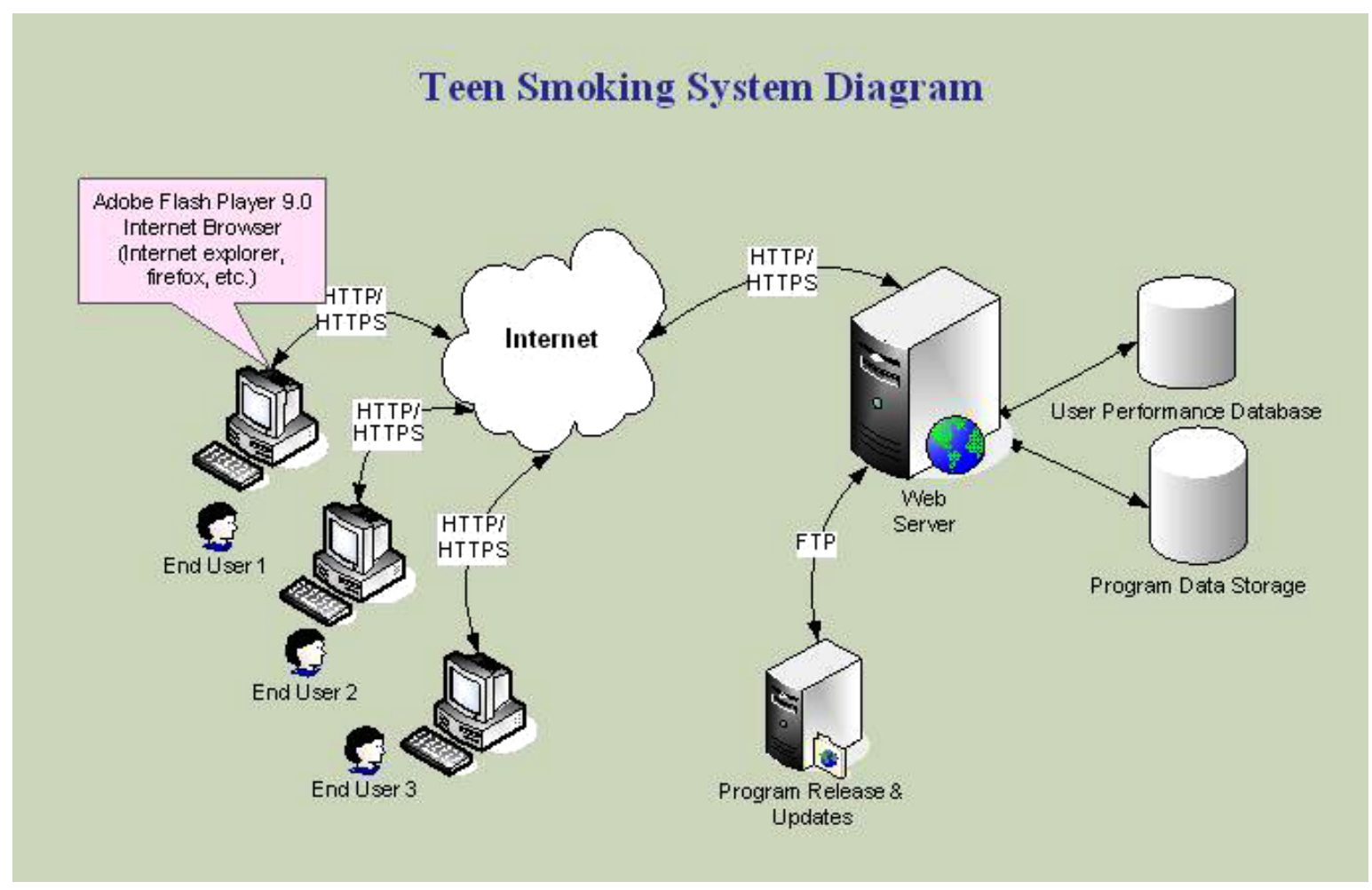

Fig. (3). A visual of the teen smoking system diagram. Multiple users can access the mini game online and play simultaneously.

\section{CONCEPTUAL DESIGN AND STORYBOARD}

After discussions with teen smoking experts, it was decided to retarget the product at high school juniors and seniors since these younger crowds tend to smoke during or after school activities, in the high school bathrooms, in their cars, and at peer's houses. In fact, about $25 \%$ of high school students in the United States use some type of tobacco product and nearly half report at least trying them [17]. We also recognize the influence parents play in these students' lives. The CDC suggests that parental smoking can promote similar behaviors in adolescents [17]. Based on these factors, we designed environments based on a teenager's home life and school activities to reflect pressures to smoke by their peers or older siblings who smoke. Teens can easily get cigarettes from other friends, brothers or sisters, or even by stealing them from their parents. Thus, the goal of the program is to stay smoke free at home and school for as long as possible while being educated and informed on smoking cessation. When fighting a craving, users can play the mini games for distraction, and will receive a reward if he/she hasn't smoked for a certain period. 


\section{3D OBJECT MODELING AND VIRTUAL WORLD DEVELOPMENT}

Based on conceptual input from teen participants, the home structure was designed and developed in to Macromedia Flash. In addition to the main frame, our artists created realistic 3D object models using 3D Studio Max, rendering the collection of objects into everyday scenes. The 3D objects included a desk, a laptop computer, an ashtray, and a toilet amongst other things. Our programmers collaborated with 3D artists to overcome technical issues such as performance, screen resolution, and environment loading (Figs. 3 and $\mathbf{4}$ ).

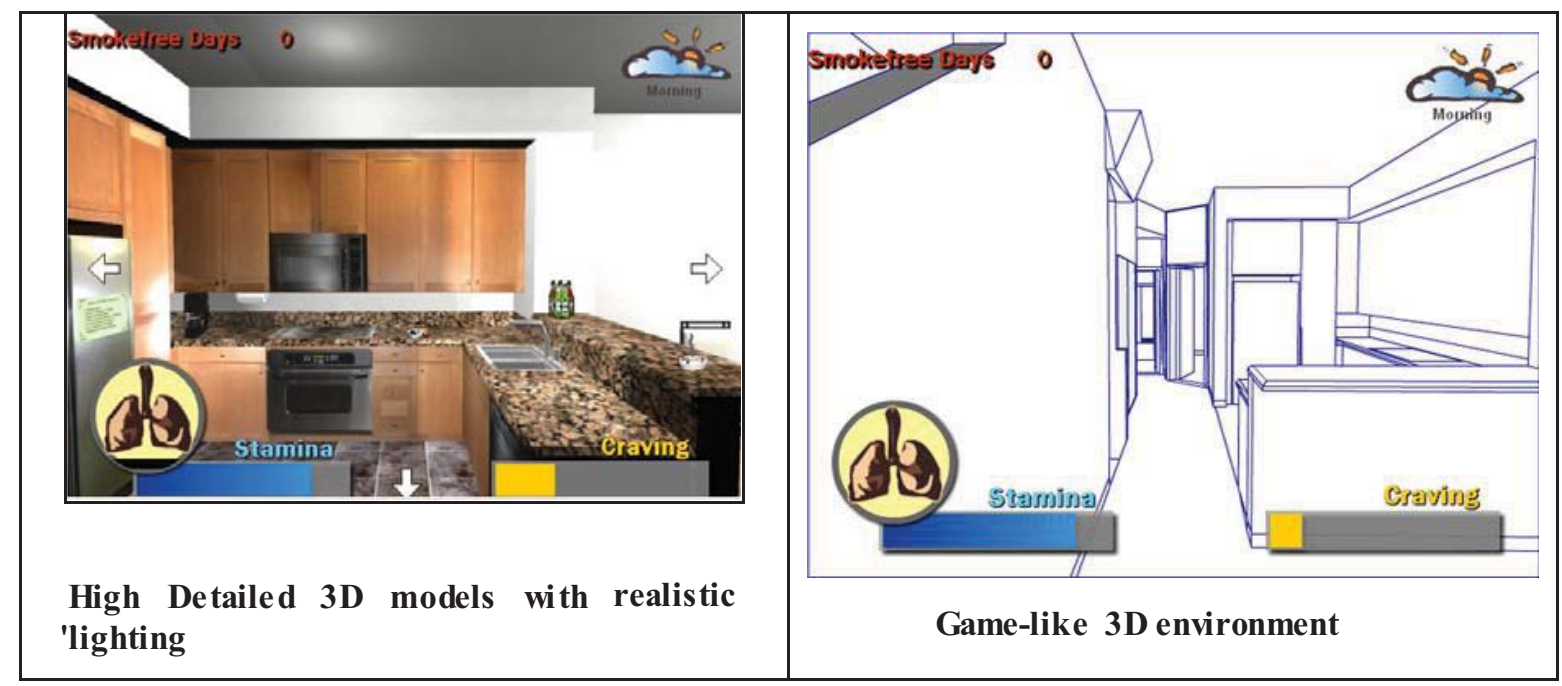

Fig. (4). The 3D environments are constructed in multiple stages, allowing for greater accuracy and realism in the environment.

We believe that one of the first steps in making our smoking cessation program effective was to capture and sustain the interest of the users. Thus, we catered to the teenager's generation by creating new-age, realistic environments using high polygon 3-dimensional models and vectors that provide a very polished and modern ambience. To further accommodate our audience, we chose scenarios and situations to which they can easily relate. For example, the two main environments are a teenager's home and school, which are places where teenagers typically spend the majority of their time. We chose a first person view to add realism and immersion to the game. The game was developed using Macromedia Flash, which is not only popular among the younger generation, but also facilitates easy web-based access for the users.

Throughout the program, users see several smoking cessation related indicators on the screen. These include a craving bar, stamina bar, lung icon, and a smoke-free day counter. Since craving plays a significant role in smoking cessation, we want to assist the user in learning to control his or her craving level. The craving bar illustrates the user's craving level for smoking a cigarette, which the user must keep at a low level by either finding alternative activities to do or simply giving in to their craving and smoking, just as they would in real life. If the user chooses to smoke, the lung icon, ranging from a shade of beige to black, will darken and the smoke-free day counter will be set to zero. If he or she fails to keep the craving level low, the bar will turn red, and the user will hear a heart beating increasing in loudness and the screen will fluctuate between bright and normal conditions. One of the effects of smoking is a decrease in energy, which is where the stamina bar comes into play. The stamina bar keeps track of the user's energy level, which determines the number of activities he or she can participate in. Each day it starts at a maximum level and decreases gradually as time goes by. Doing activities also uses stamina. The decrease rate is dependent on the lung condition. The healthier the lung (brighter), the slower the stamina decreasing rate. When the stamina bar reaches its minimum, the player must sleep or eat to regain energy. An additional time-of-day indicator icon is also displayed to help guide the player to certain activities and keep track of the day.

According to smoking cessation strategies and tips, the selection of a quit date is one of the first steps to successful cessation [18]. At the start of the program, then, the user is in his or her bedroom where he or she must select a quit date from the provided calendar before participating in further activities. Another recommended strategy is to remove all smoking paraphernalia in the environment if possible. Thus the player is presented with this option in the game to help decrease his or her craving level. The user will find various smoking cues, such as cigarettes, coffee, alcohol, and ashtrays, placed throughout the house. They will then be given choices on what to do with those paraphernalia. At 
school, the user will be faced with peer pressure and his or her craving when other students offer cigarettes.

The user will also discover several mini-games and activities that are available to help him or her deal with the craving. Most of these activities distract and reduce smoking cravings, while others present smoking cues to challenge the user's real-life craving. One of the activities in the home is the option of taking a bath, which is another method of suppressing craving. While the user is "taking a bath," he or she plays a mini-game of shooting rubber ducks with a water gun and tries to acquire as many points as possible. Not only does this game distract the user from wanting to smoke, but it is also a source of entertainment for him or her. Another optional activity in the house is making a sandwich because while smokers eat, they often do not crave tobacco. This activity, then, reduces the player's craving level in game. However, after eating, the craving increases because that is when many smokers tend to smoke. Yet another distraction technique included in the house is a drumming game, where the user is required to remember and follow a drumming pattern. The memorization involved in the game increases immersion, and thus distracts the user from his or her craving.

In real-life, if one wants to maintain or improve lung condition, one can choose to exercise. The game presents a similar option. If the user decides to take a smoke, his or her lung icon darkens each time. To improve lung condition and turn the lung icon to its normal color again, the user can stop smoking and do exercise. These messages, together with other smoking cessation tips, are conveyed to teenagers in an entertaining and engaging way.

Statistics of each user's condition and actions are recorded and displayed on the right-hand side of the main screen. These include the maximum number of in-game smoke-free days, number of cigarettes the user has taken, the types of activities and mini-games he or she has played, health condition, etc. This data is useful for analysis and comparison at the end of the game. By looking at this table, the player or physician will be able to tell how well or bad the user did ingame. It can also act as a reminder to the user about what can be done in real-life to fight the urge to smoke and how to react to smoking cues.

\section{CONCLUSION}

VRMC approached teen smoking cessation in a revolutionary way by utilizing advanced technologies, validated research, and invaluable input from teenagers themselves to create an anti-smoking environment to help teens quit smoking for good. In summary, the TeenSmoking program is a tool developed for teens, by teens to aid in the fight against the most preventable cause of death in the United States.

In the future, researchers at VRMC hope to continue to implement widely available teen smoking cessation programs. The current web based TeenSmoking program is easily accessible, easy to understand and engaging. But in order to broaden the audience and enhance the playing experience, there are several functions and ideas we would like to expand on and implement in the next versions.

First, the current version of the TeenSmoking project is fun and graphically enhanced. However, the development team would like to expand the game play to make it even more engaging. There are several in-game functions and contents that would allow us to do so; for instance, a reward system for the player for staying smoke-free for a certain number of days. Such a reward may be a poster that the player can put in his room, or a nicotine patch item that would slow down the craving increment in the game; a virtual online shop for user to purchase furniture, decorations, and items to use to customize the virtual house; a part-time job system where the user needs to work (more mini-games involved) for money that can then be used to buy items in the online shop.

Multiplayer functionality can greatly improve the user's experience while he or she is in the virtual space. With multiplayer functionality enabled, users can compete, overcome obstacles, and form alliances with one another. The multiplayer version of the TeenSmoking program would include 2 or more users to be involved in the program at the same time. Users could have the option to become "quitting buddies" in the program and try to achieve goals together. On the other hand, one user could choose to be a smoker and try to stop the other user from quitting smoking. They would compete in different types of mini-games to determine who has the greater willpower. Even more users can join in for greater fun.

As more players join the game, there will eventually be a need to make each user identifiable and unique. To meet these criteria, user would be able to create their own account accompanied by a unique "user ID" and create their own virtual avatar with customizable appearance and outfit. One could even upload their own picture in the process of creating their avatar. A database server will be set up in order for each user to save their account, avatar, and game progress and retrieve them later. 
The TeenSmoking project team also has plans to set up an online forum or message board for users to interact by posting opinions and questions about the game, smoking cessation, or related topics. This would be a great place for the community to discuss the subject, tell successful stories, and give advice to people looking to quit. The forum could also be utilized by VRMC to post upcoming events, announcements and useful links on the board.

When the newest version of the TeenSmoking project goes public, VRMC could organize events or visits to schools and institutions to promote a smoke-free environment with the game. There would also be competitions that give out real prizes to those who play the game and successfully quit smoking within a certain period. Overall, the creation and dissemination of this game is intended to educate, encourage, and help teenagers overcome nicotine dependence. This initial exploration produced successful results and has set the stage for more comprehensive use of virtual reality in curbing smoking addictions. The expansion of this program can lead to improved research and understanding of effective smoking cessation tools and programs for our youth. Extending the reach of this program beyond high school juniors and seniors is essential to its success as an effective and widely accessible tool.

\section{ETHICS APPROVAL AND CONSENT TO PARTICIPATE}

Not applicable.

\section{HUMAN AND ANIMAL RIGHTS}

No Animals/Humans were used for studies that are base of this research.

\section{CONSENT FOR PUBLICATION}

Not applicable.

\section{CONFLICT OF INTEREST}

The authors declare no conflict of interest, financial or otherwise.

\section{ACKNOWLEDGEMENTS}

We thank the National Institutes of Health (NIH), National Institute on Drug Abuse (NIDA) for funding the this study. We also thank the student participants who were willing to spend time with our clinical team building the virtual environments.

\section{REFERENCES}

[1] Burden of Tobacco Use in the U.S. Centers for Disease Control and Prevention. 2015. Available at: https:/www.cdc.gov/tobacco/campaign /tips/resources/data/cigarette-smoking-in-united-states.html

[2] Klein JD, Havens CG, Carlson EJ. Evaluation of an adolescent smoking-cessation media campaign: GottaQuit.com. Pediatrics 2005; 116(4): 950-6.

[http://dx.doi.org/10.1542/peds.2005-0492] [PMID: 16199707]

[3] Challenges When Quitting. Smokefree.gov. Available at: https://www.smokefree.gov/challenges-when-quitting. (Accessed on March 28, 2017)

[4] Health Effects of Cigarette Smoking National Center for Chronic Disease Prevention and Health Promotion 2016. Available at: https://www.cdc.gov/tobacco/data_statistics/fact_sheets/health_effects/effects_cig_smoking/

[5] The Smoking Zine: Using the Internet for Smoking Prevention with Youth 2016. Available at: https://www.ptcc-cfc.on.ca/cms /One.aspx?portalId=97833pageId;=114647

[6] Sussman S, Sun P, Dent CW. A meta-analysis of teen cigarette smoking cessation. Health Psychol 2006; $25(5): 549-57$. [http://dx.doi.org/10.1037/0278-6133.25.5.549] [PMID: 17014271]

[7] Ahmann N. Teens help researchers create internet environment to curb teen smoking - cybertherapy and rehabilitation. cybertherapy and rehabilitation. 2014. Available at: http://www.cybertherapyandrehabilitation.com/2014/06/ teens-help-researchers-create-internetenvironment-curb-teen-smoking/

[8] Lee J, Lim Y, Graham SJ, et al. Nicotine craving and cue exposure therapy by using virtual environments. Cyberpsychol Behav 2004; 7(6): $705-13$.

[http://dx.doi.org/10.1089/cpb.2004.7.705] [PMID: 15687806]

[9] Pericot-Valverde I, Secades-Villa R, Gutiérrez-Maldonado J, García-Rodríguez O. Effects of systematic cue exposure through virtual reality on cigarette craving. nicotine and tobacco research. Nicotine Tob Res 2014; 16(11): 1470-7.

[10] Mellentin AI, Nielsen B, Nielsen AS, Yu F, Stenager E. A randomized controlled study of exposure therapy as aftercare for alcohol use 
disorder: study protocol. BMC Psychiatry 2016; 16(1): 112.

[http://dx.doi.org/10.1186/s12888-016-0795-8] [PMID: 27098817]

[11] Zhang Y, Ndasauka Y, Hou J, Chen J. Cue-induced behavioral and neural changes among excessive internet gamers and possible application of cue exposure therapy to internet gaming disorder. Front Psychol 2016; 7: 675.

[12] Gutiérrez-Maldonado J, Pla-Sanjuanelo J, Ferrer-García M. Cue-exposure software for the treatment of bulimia nervosa and binge eating disorder. Psicothema 2016; 28(4): 363-9.

[http://dx.doi.org/10.7334/psicothema2014.274] [PMID: 27776602]

[13] Culbertson CS, Shulenberger S, De La Garza R, Newton TF, Brody AL. Virtual reality cue exposure therapy for the treatment of tobacco dependence. J Cyber Ther Rehabil 2012; 5(1): 57-64. [PMID: 25342999]

[14] Lee JH, Lim Y, Wiederhold BK, Graham SJ. A functional magnetic resonance imaging (FMRI) study of cue-induced smoking craving in virtual environments. Appl Psychophysiol Biofeedback 2005; 30(3): 195-204. [http://dx.doi.org/10.1007/s10484-005-6377-z] [PMID: 16167185]

[15] Wiederhold BK, Rizzo AS. Virtual reality and applied psychophysiology. Appl Psychophysiol Biofeedback 2005; 30(3): 183-5. [http://dx.doi.org/10.1007/s10484-005-6375-1] [PMID: 16167183]

[16] Lee JH, Ku J, Kim K, et al. Experimental application of virtual reality for nicotine craving through cue exposure. Cyberpsychol Behav 2003; 6(3): 275-80.

[http://dx.doi.org/10.1089/109493103322011560] [PMID: 12855083]

[17] Youth and Tobacco Use. Centers for Disease Control and Prevention. Centers for Disease Control and Prevention. 2016. Available at: https://www.cdc.gov/tobacco/data_statistics/fact_sheets/youth_data/tobacco_use/

[18] Dr. Steven Melemis, I Want to Change My Life. How to Quit Smoking. Addictions and Recovery. 2017. Available at: https://www.addictionsandrecovery.org/quit-smoking-plan.htm

(C) 2017 Wiederhold et al.

This is an open access article distributed under the terms of the Creative Commons Attribution 4.0 International Public License (CC-BY 4.0), a copy of which is available at: https://creativecommons.org/licenses/by/4.0/legalcode. This license permits unrestricted use, distribution, and reproduction in any medium, provided the original author and source are credited. 